\title{
Digoxin- and Digitoxin-Like Immunoreactive Substances in Amniotic Fluid, Cord Blood, and Serum of Neonates
}

\author{
HIROYOSHI EBARA, SHIGEYOSHI SUZUKI, KANJI NAGASHIMA, TAKENOBU KOIZUMI, \\ AKIRA NISHIDA, YUZURU KANBE, AND TAKAYOSHI KUROUME \\ Department of Pediatrics, Gunma University School of Medicine and Division of Neonatology, Gunma Children's \\ Medical Center Maebashi, Gunma, Japan
}

\begin{abstract}
Using four different digoxin kits, it was disclosed that the majority of various samples including amniotic fluid, cord blood, and serum from neonates contained substantial levels of digoxin-like immunoreactive substance. The differences in data seemed to be due to the range of epitopes which are recognized by antidigoxin antiserum. The day-to-day studies on sera serially obtained from infants at birth to 48 days old revealed that the level of the substance $(0.31 \pm 0.12 \mathrm{ng} / \mathrm{ml})$ in sera of the 1-dayold neonates rapidly declined to the level of $0.1 \mathrm{ng} / \mathrm{ml} \mathrm{by}$ the 2nd postnatal wk and thereafter gradually declined. The immunological specificity and accuracy of the detection of digoxin-like immunoreactive substance was confirmed by a sample dilution test, a recovery test for standard digoxin, and an absorption test with antidigoxin antiserum. The amniotic fluid and cord blood also contained four to eight times more of a digitoxin-like immunoreactive substance than they did digoxin-like immunoreactive substance. A significant correlation was observed between the levels of digoxin-like immunoreactive substance and of digitoxin-like immunoreactive substance $(p<0.01)$. (Pediatr Res 20: 28-31, 1986)
\end{abstract}

\section{Abbreviations}

DLIS, digoxin-like immunoreactive substance DTLIS, digitoxin-like immunoreactive substance EIA, enzyme immunoassay

RIA, radioimmunoassay

Recent reports (1-3) renewed our attention toward the falsepositive digoxin measurements in the plasma of premature infants (4). From the clinical viewpoint, these observations raise some important questions. The first question is whether the falsepositive digoxin measurement really indicates the presence of a DLIS which leads to an erroneous judgment about the level of digoxin in monitoring of neonatal samples. The second question is whether there is any similarity in biochemical specificity between DLIS and the so-called "ouabain-like substances" detected in other organs or body fluids (5-13). It seems that previous reports $(1-3)$ have not yet provided substantial evidence for their conclusion that the substance is not a product of technical or nonimmunological false positivity. Therefore, in this communication, we tried to confirm the previous findings using

Received September 6, 1984; accepted August 19, 1985

Address for correspondence Hiroyoshi Ebara, M.D., Department of Pediatrics, Gunma University School of Medicine, 3-39-22 Showa-machi, Maebashi-shi, Gunma-ken, Japan. amniotic fluid, cord blood, and serum specimen from neonates and also to evaluate immunological specificity of the reaction and presence of a DTLIS.

\section{MATERIALS AND METHODS}

Thirty-one amniotic fluid and 53 cord blood samples were obtained from mothers who had not received any digitalis glycosides during pregnancy and labor. One hundred eleven sera were also obtained from 23 neonates over 35 -wk gestational age who were delivered from healthy mothers who had not been on digitalis therapy. The mean and range of birth weight of the neonates were $3264 \mathrm{~g}$ and $2016-4420 \mathrm{~g}$, respectively. The investigation was approved by the ethical committee of the hospital and informed parental consent was obtained for blood sampling. All samples were stored at $-20^{\circ} \mathrm{C}$ in separate small quantities to avoid unnecessary freezing and thawing, and analyzed at various intervals, always within 30 days of collection.

For the detection of DLIS, one EIA kit and three RIA kits available in Japan were used: kit A (Markit Digoxin, DainipponSeiyaku, Osaka, Japan); kit B (Amerlex Digoxin RIA kit, Amersham, UK); kit C (Spac Digoxin kit, Daiichi Isotope, Tokyo, Japan) and kit D (Gammacoat ${ }^{125}$ I-Digoxin RIA kit, Travenol Laboratories, Inc. Cambridge, MA). For the detection of DTLIS, an EIA kit (Markit Digitoxin) was used. As a separation technique, a solid phase method (kits $B, C$, and D), and a double antibody method (kit $A$ and a kit for DTLIS) were used. To increase the sensitivity of assay, first antiserum diluted to 1 in 3 was used in kit $A$ and the preincubation of samples and antiserum at $37^{\circ} \mathrm{C}$, for $30 \mathrm{~min}$ was carried out in kit B. Other assay procedures were performed in duplicates according to the respective manufacturer's instructions.

The cross-test was performed according to the protocol of the kit, except for a mutual exchange of the digoxin antisera between kit $\mathrm{A}$ and kit $\mathrm{B}$.

In the recovery experiments, crystaline digoxin (Sigma Chemical Co., St. Louis, MO) dissoved in $60 \%$ ethanol was added to the sample at a concentration of $1.5 \mathrm{ng} / \mathrm{ml}$. The recovery experiments were done according to the method reported by Valdes et al. (3).

In the absorption test, $500 \mu \mathrm{l}$ of sample and the sediment of 1 $\mathrm{ml}$ antidigoxin-coupled bead suspension obtained from kit B were incubated at room temperature. After $15 \mathrm{~min}$ incubation, the mixture was centrifuged and the supernatant was transferred to another tube containing the fresh antidigoxin-coupled beads. The same absorbing procedures were repeated three times and the final supernatant was subjected to the RIA. To examine the possibility of uncoupling antidigoxin antibody from beads into supernatants in the absorption process, the lyophilized standard digoxin serum was dissolved with the supernatant which under- 
went an absorption process by the antidigoxin-coupled beads, and the recovery rate of digoxin was examined. The uncoated beads with antidigoxin antiserum were used as control in the absorbing procedure to rule out the nonspecific binding of DLIS to beads.

Statistical analysis was done by Student's $t$ test and paired $t$ test. All values in the text are means $\pm \mathrm{SD}$.

\section{RESULTS}

The levels $(\mathrm{ng} / \mathrm{ml})$ of DLIS in amniotic fluids were $1.35 \pm$ 0.33 in kit $\mathrm{A}$ and $0.38 \pm 0.16$ in kit $\mathrm{B}$. Those in cord blood were $1.33 \pm 0.17$ in kit $A$ and $0.45 \pm 0.07$ in kit $B$. The magnitude of values for DLIS measured by four different kits on each of 10 samples of amniotic fluid and cord blood is shown in Table 1. Although the values obtained were highly variable between the kits, the majority of samples contained material that competes with the reaction between enzyme or ${ }^{125}$ I-labeled digoxin and antidigoxin. In particular, the values obtained by kit $A$ were approximately three times higher than those obtained by the other three kits. The large discrepancy in the data prompted us to measure the digoxin levels twice in the same samples, using the sera exchanged between kit A and kit B. As shown in Table 2 , there was a tendency to obtain lower values when the antiserum from kit $B$ was used for the assay. The standard and dilution curves of kit $A$ when the antiserum from kit $B$ was used are presented as Figure 1 . The mean $\pm \mathrm{SD}$ ratio of the data measured with the antiserum from kit $B$ against the data measured by kit $\mathrm{A}$ according to the original protocol was $62.0 \pm$ $14.0 \%$.

In the studies on the sera which were serially collected from neonates of 1-48 days old, the levels of DLIS on the 1st postnatal day were not statistically different from those of nonpaired cord sera, then it rapidly declined to the level of $0.1 \mathrm{ng} / \mathrm{ml}$ by the $2 \mathrm{nd}$ postnatal wk and thereafter gradually declined (Fig. 2).

The studies, which were done to demonstrate the immunological specificity and accuracy of digoxin measurement, presented the following results. The dilution curves obtained with amniotic fluid and cord blood paralleled that of digoxin standard (Fig. 3). In the recovery test, we added the known amount of digoxin to each of three samples of amniotic fluid and cord blood. The average percent recovery of digoxin in amniotic fluid and cord blood were $72.0 \pm 13.9$ and $81.5 \pm 3.7 \%$, respectively, and there was an additive interference that depended on the magnitude of the endogenous baseline value. The DLIS levels around $0.3 \mathrm{ng} /$ $\mathrm{ml}$ detected in amniotic fluid and cord blood before absorption were reduced to an undetectable level by absorption with antidigoxin-coupled bead (Table 3). The standard serum dissolved with the distilled water which then underwent an absorption process showed the titer to be compatible with that of original serum. The nonspecific binding to the uncoated beads with antidigoxin antiserum was negligible (Table 3).

Finally we measured digitoxin values by EIA for digitoxin on the nine paired samples of amniotic fluid and cord blood. Amniotic fluid and cord blood contained DTLIS levels of $5.7 \pm 2.8$ and $10.5 \pm 2.7 \mathrm{ng} / \mathrm{ml}$, respectively (Table $4 B$ ). The dilution and recovery test in this assay was shown in Table $4 A$. The crossreaction with digoxin was below $1 \%$ and a significant correlation was observed between the levels of DLIS and DTLIS in amniotic fluid or cord blood ( $p<0.01$; point by point).
Table 2. DLIS in amniotic fluid or cord blood measured by the digoxin assay kits with the antisera mutually exchanged between them

\begin{tabular}{|c|c|c|c|c|}
\hline \multirow{4}{*}{ Sample no. } & \multicolumn{4}{|c|}{$\begin{array}{l}\text { Digoxin-like immunoreactive substance } \\
\qquad(\mathrm{ng} / \mathrm{ml}) \text { assayed by }\end{array}$} \\
\hline & \multicolumn{2}{|c|}{ Kit A (EIA) } & \multicolumn{2}{|c|}{ Kit B (RIA) } \\
\hline & \multicolumn{4}{|c|}{ Antidigoxin from } \\
\hline & Kit A & Kit B & Kit B & Kit A \\
\hline \multicolumn{5}{|l|}{ Amniotic fluid } \\
\hline 1 & 1.05 & 0.48 & 0.28 & \\
\hline 2 & 1.15 & 0.49 & 0.20 & \\
\hline 3 & 1.30 & 0.46 & 0.27 & \\
\hline 4 & 1.20 & 0.54 & 0.33 & \\
\hline 5 & 1.15 & 0.52 & 0.51 & $\begin{array}{l}\text { Technically } \\
\text { impossible }\end{array}$ \\
\hline \multicolumn{5}{|l|}{ Cord blood } \\
\hline 1 & 1.45 & 0.44 & 0.49 & \\
\hline 2 & 1.45 & 0.46 & 0.46 & \\
\hline 3 & 1.35 & 0.45 & 0.42 & \\
\hline 4 & 1.40 & 0.47 & 0.50 & \\
\hline 5 & 1.50 & 0.45 & 0.56 & \\
\hline
\end{tabular}

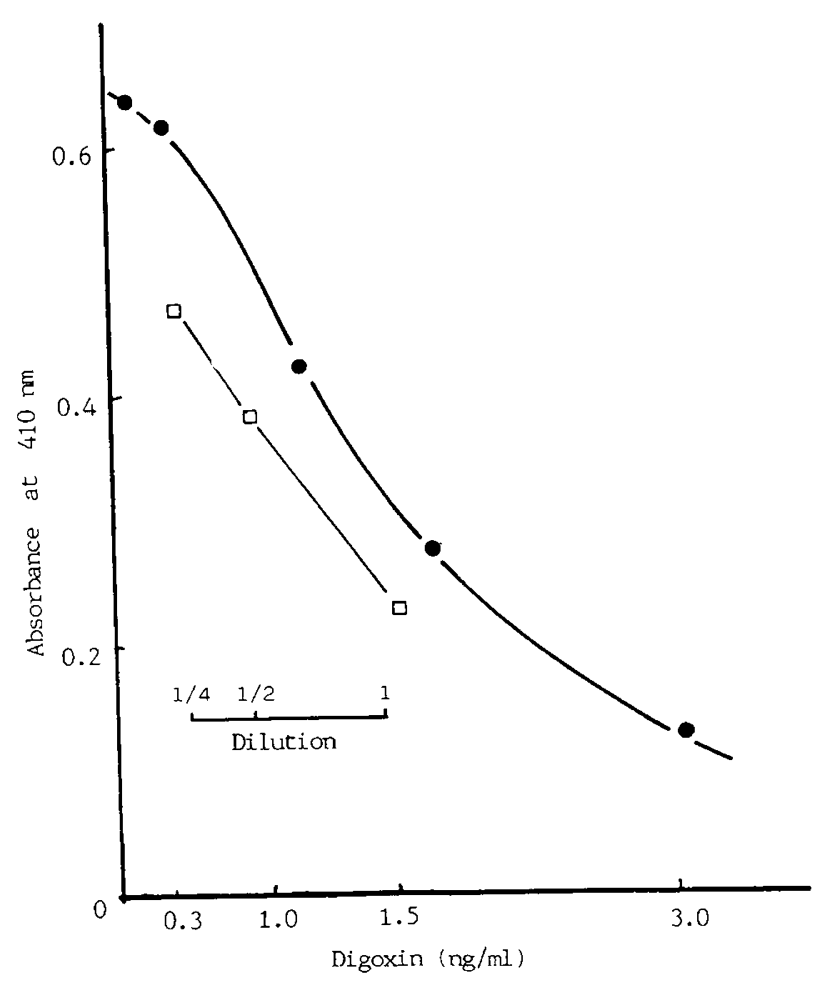

Fig. 1. The standard curve (- - ) and dilution curve of standard serum $(\square-\square)$ in the assay when the antiserum from kit B was used in kit A.

Table 1. DLIS in amniotic fluid and cord blood measured by four different digoxin assay kits (mean $\pm S D)$

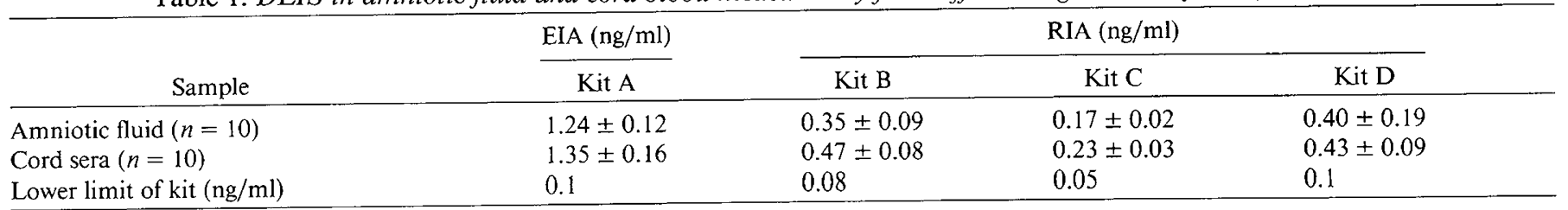




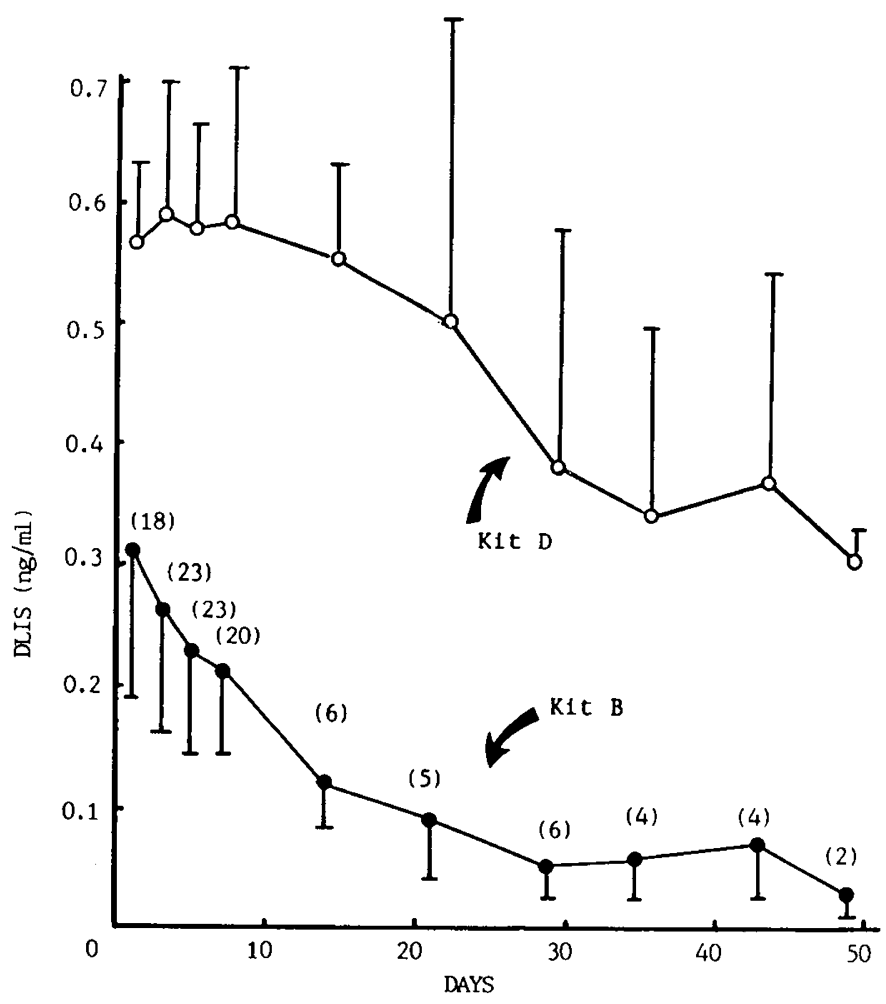

Fig. 2. Serial observation of DLIS in sera from neonates. In this study the same samples were examined by kits B and D. Figures in parentheses denote sample numbers.

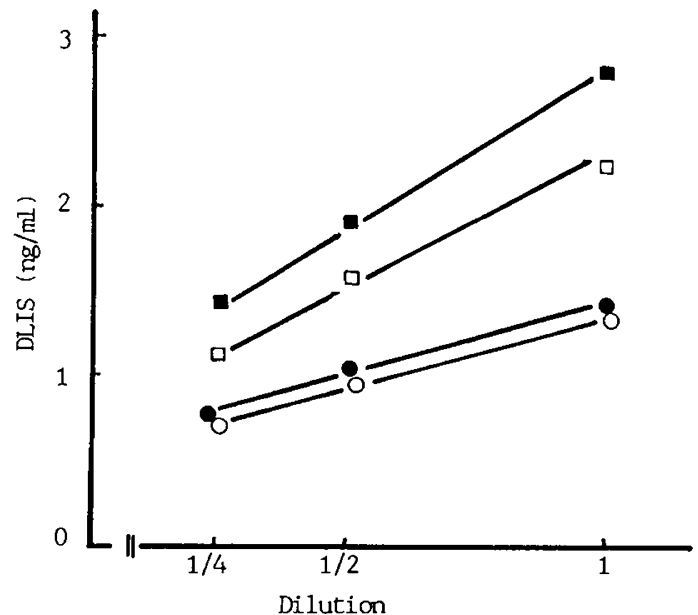

Fig. 3. The dilution curves in amniotic fluid ( $\square$ and $\square$ ) and cord blood ( and $\mathrm{O})$ detected by kit $\mathrm{A}$.

\section{DISCUSSION}

It has become standard practice to monitor digoxin therapy by RIA methods. In daily practice, we sometimes experience that in neonates who have never received digoxin, the drug is detected by RIA in their blood samples, or that infants who are taking digoxin show a high level of digoxin discordant with administered doses. Recent reports by several groups (1-3) encouraged us to study systematically the digoxin level in amniotic fluid, cord blood, and sera of neonates not receiving digoxin therapy, using four different kits. Since only small sample volumes of plasma were available, it was not possible to measure simultaneously concentration in the same samples by several assay kits. However, we are able to conclude that those samples contain DLIS and that the substance detected in serum of premature infants

Table 3. The absorption of digoxin-like immunoreactive substance detected in amniotic fluid or cord blood

\begin{tabular}{|c|c|c|c|}
\hline \multirow[b]{2}{*}{ Sample no. } & \multicolumn{3}{|c|}{$\begin{array}{c}\text { DLIS }(\mathrm{ng} / \mathrm{ml}) \\
\text { assayed by kit B }\end{array}$} \\
\hline & & Before absorption & After absorption \\
\hline \multirow[t]{3}{*}{ Amniotic fluid } & 1 & 0.22 & Undetectable \\
\hline & 2 & 0.31 & Undetectable \\
\hline & 3 & 0.39 & Undetectable \\
\hline \multirow[t]{3}{*}{ Cord blood } & 1 & 0.32 & Undetectable \\
\hline & 2 & 0.39 & Undetectable \\
\hline & 3 & 0.42 & Undetectable \\
\hline
\end{tabular}

Absorbed by uncoated control beads with antidigoxin serum

$\begin{array}{lll}\text { Standard serum } & & \\ 1 & 0.34 & 0.30 \\ 2 & 0.68 & 0.64 \\ 3 & 1.58 & 1.62\end{array}$

Resolved with distilled water

Standard serum

\begin{tabular}{lll}
1 & 0.34 & 0.31 \\
2 & 0.68 & 0.69 \\
3 & 1.58 & 1.73 \\
\hline
\end{tabular}
which underwent an absorption process
Resolved with the supernatant

gradually declines after birth. Recently Seccombe et al. (14) reported that a distinct peak DLIS concentration in premature infants occurred several days after birth. Although the reason of discrepancy between our data and theirs is unclear, it might be due to the difference of subjects. The mean birth weights in our subjects were more than $1500 \mathrm{~g}$, while those in the report (14) were less than $1500 \mathrm{~g}$.

To determine the meaning of the large difference between the data obtained by kits $A$ and $B$, we measured the digoxin level twice in the same sample, using the antisera exchanged between the kits. Although we could not perform a complete two-way confirmation due to technical difficulties arising from differences between the protocols in the two kits, it seems that the values of digoxin in samples depend on the range of epitope which the antibody can recognize.

Previous authors $(1-3)$ concluded that the apparent falsepositive value was not attributable to technical error. The immunological specificity of reaction, however, has not yet been fully elucidated. The false-positive result might be due to a substance which nonimmunologically inhibits the reaction between antidigoxin antibody and labeled digoxin, since most of the assay kits for digoxin use the competition technique $(15,16)$, not the sandwich technique (17), as a principle. By the absorption and dilution test, we confirmed that the substance which competes with the labeled-digoxin is also immunologically reactive with antidigoxin antibody. A small variation of data within kits will also neglect the technical or nonimmunological false-positivity.

Recently, several reports have appeared suggesting the presence of endogenous digitalis-like substances in various organs or body fluids (5-13). Besides the presence of DLIS, DTLIS was detected in amniotic fluid or cord blood in our study. It was not crossreactive with DLIS and there was a significant correlation between the levels of DLIS and DTLIS. This finding indirectly indicates that there are multiple substances immunologically 
Table 4. DLIS and DTLIS in amniotic fluid and cord blood

A. Control data of assay in DTLIS

1. Recovery test (unit: $\mathrm{ng} / \mathrm{ml}$ )

\begin{tabular}{lccccc}
\hline & & Sample & Added & Observed & Recovery (\%) \\
\hline Cord serum & 1 & 5.0 & 15.0 & 19.5 & 96.7 \\
& 2 & 6.8 & 15.0 & 22.0 & 101.3 \\
& 3 & 5.2 & 15.0 & 19.7 & 96.7 \\
Amniotic fluid & 4 & 2.5 & 15.0 & 16.6 & 94.0 \\
& 1 & 6.1 & 15.0 & 24.0 & 119.3 \\
& 2 & 2.3 & 15.0 & 17.8 & 103.3 \\
& 3 & 1.0 & 15.0 & 18.2 & 114.7 \\
& 4 & 0.9 & 15.0 & 17.5 & 110.7
\end{tabular}

2. Dilution test (Unit: $\mathrm{ng} / \mathrm{ml}$ )

Dilution rate

\begin{tabular}{lrrrr}
\cline { 3 - 4 } Sample & & $\times 1$ & $\times 1 / 2$ & $\times 1 / 5$ \\
\hline Cord serum & 1 & 11.5 & 6.8 & 3.2 \\
& 2 & 12.0 & 6.5 & 3.6 \\
& 3 & 8.0 & 5.7 & 2.5 \\
Amniotic fluid & 1 & 5.0 & 3.0 & 0.7 \\
& 2 & 3.8 & 1.9 & 0.5 \\
& 3 & 3.4 & 1.8 & 0.3 \\
& 4 & 2.8 & 0.7 & 0.2 \\
& 4 & 3.1 & 0.7 & 0.5
\end{tabular}

B. Comparison between DTLIS and DLIS

\begin{tabular}{lllllc} 
& \multicolumn{2}{c}{ Amniotic fluid $(\mathrm{ng} / \mathrm{ml})$} & & \multicolumn{2}{c}{ Cord blood $(\mathrm{ng} / \mathrm{ml})$} \\
\cline { 2 - 3 } \cline { 5 - 6 } Sample & DLIS & DTLIS & & DLIS & DTLIS \\
\hline 1 & 2.05 & 9.8 & & 1.20 & 12.5 \\
2 & 1.15 & 3.8 & & 1.10 & 9.2 \\
3 & 1.30 & 3.2 & 1.35 & 10.3 \\
4 & 1.15 & 5.6 & 1.20 & 9.5 \\
5 & 1.85 & 6.0 & 1.20 & 8.6 \\
6 & 1.20 & 3.5 & 1.20 & 8.6 \\
7 & 2.30 & 10.8 & 1.15 & 7.0 \\
8 & 1.25 & 4.2 & 1.60 & 15.0 \\
9 & 1.15 & 4.4 & 1.50 & 14.0 \\
Mean $\pm \mathrm{SD}$ & $1.49 \pm 0.45$ & $5.7 \pm 2.8$ & $1.28 \pm 0.17$ & $10.5 \pm 2.7$ \\
\hline
\end{tabular}

similar to digitalis in amniotic fluid, cord blood, or peripheral blood of neonates. To understand the potential importance of the digitalis-like substances in the unique physiology of neonates will require further investigation.

\section{REFERENCES}

1. Pudek MR, Seccombe DW, Whitfield MF, Ling E 1983 Digoxin-like immunoreactivity in premature and full-term infants not receiving digoxin therapy. N Engl J Med 308:904-905

2. Pudek MR, Seccombe DW, Jacobson BE, Whiterfield MF 1983 Seven different digoxin immunoassay kits compared with response to interference by a digoxin-like immunoreactive substance in serum from premature and fullterm infants. Clin Chem 29:1972-1974

3. Valdes R Jr, Graves SW, Brown BA Landt M 1983 Endogenous substance in newborn infants causing false positive digoxin measurements. J Pediatr 102:947-950

4. Besch HR Jr Hefferd S, Lake M, Hurwitz R, Watanabe AM 1976 False elevation of apparent digoxin levels in plasma of premature infants. Clin Chem 22:1168

5. Beyers AD, Spruyt LL, Seifart HI, Kriegler A, Parkin DP, Van Jaarsveld PP 1983 Endogenous digoxin-like material. S Afr Med J 64:42

6. Fishman MC 1979 Endogenous digitalis-like activity in mammalian brain. Proc Natl Acad Sci USA 76:4661-4663

7. Graves SW, Brown B, Valdes R 1983 An endogenous digoxin-like substance in patients with renal impairment. Ann Intern Med 99:604-608

8. Graves SW, Valdes R Jr, Brown BA, Knight AB, Craig HR 1984 Endogenous digoxin-immunoreactive substance in human pregnancies. J Clin Endocrinol Metab 58:748-75

9. Gruber KA, Rudel LL, Bullock BC 1982 Increased circulating levels of an endogenous digoxin-like factor in hypertensive monkeys. Hypertension $4: 348-354$

10. Halperin J, Schaeffer R, Galvez L, Malave S 1983 Ouabain-like activity in human cerebrospinal fluid. Proc Natl Acad Sci USA 80:6101-6104

11. Haupert GT Jr, Sancho JM 1979 Sodium transport inhibitor from bovine hypothalamus. Proc Natl Acad Sci USA 76:4658-4660

12. Lichstein D, Samuelov S 1980 Endogenous "ouabain like" activity in rat brain. Biochem Biophys Res Commun 96:1518-1523

13. Schreiber V, Gregorova I, Pribyl T, Stepan, J 1981 Digitalis-like biological activity and immunoreactivity in chromatographic fractions of rabbit adrenal extract. Endocrinol Exp 15:229-236

14. Seccombe DW, Pudek MR, Whitfield MF, Jacobson BE, Wittmann BK, King JF 1984 Perinatal changes in a digoxin-like immunoreactive substance. Pediatr Res 18:1097-1099

15. Smith TW, Butler VP, Haber E 1972 Determination of therapeutic and toxic serum digoxin concentrations by radioimmunoassay. $\mathrm{N}$ Engl $\mathrm{J}$ Med 281:1212-1216

16. Yalow RS, Berson SA 1971 In: Odell, Daughday (eds) Principles of Competitive Protein Binding Assays. J. B. Lippencott Co., Philadelphia

17. Wide L, Bennich H, Johanson SGO 1967 Diagnosis of allergy by an in vitro test for allergen antibodies. Lancet 2:1105-1107 